\title{
Influence of Strategic Planning to Firm Performance in Agricultural Research Based Institutions of Kenya
}

\author{
Yusuf W. Musi ${ }^{1}$, E. Mukulu² \& M. Oloko ${ }^{1}$ \\ ${ }^{1}$ Agricultural Mechanization Research Institute, Katumani, Machakos, Kenya \\ ${ }^{2}$ Jomo Kenyatta University of Science \& Technology (JKUAT), Nairobi, Kenya \\ Correspondence: Y. W. Musi, Agricultural Mechanization Research Institute, Katumani, P. O. Box 340-90100, \\ Machakos, Kenya.
}

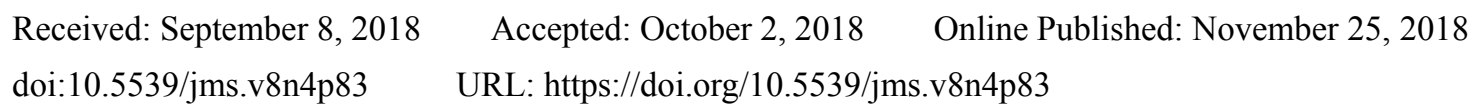

\begin{abstract}
Strategic planning is a very crucial phenomenon in all organisations. It is the tool that determines the destiny of the firm. The objective of this study was to investigate the influence of financial resource strategic planning on firm performance, to determine influence of human capital strategic planning on firm performance, to analyze the influence of material resource strategic planning on firm performance and to determine influence of information resource strategic planning on firm performance in agriculture research based institutions of Kenya. Although there had been previous international studies in this field, no literature is evident on status of the same in agriculture based research institutions in Kenya. The study comprised of former 4 major agricultural based research institutes of Kenya, namely: Kenya Agricultural Research Institute (KARI), Coffee Research Foundation (CRF), Tea Research Foundation (TRF), and Kenya Sugar Research Foundation (KeSREF). The institutions had 2922 employees in the year 2015. The study employed descriptive research design. The sample size was 352 having been arrived at using Yamane's (1967) formula. Results and conclusion of the study were that financial resources strategic planning, human capital strategic planning, material resource strategic planning and information resource strategic planning influence a firm's performance in a great way.
\end{abstract}

Keywords: strategic planning, Agricultural Research Institute, firm performance

\section{Introduction}

\subsection{Study Overview}

Over time the concept and practice of strategic planning had been embraced worldwide and across various sectors because of its perceived contribution to organisational effectiveness. Strategic planning is defined as the systematic process of envisioning a desired future and translating the vision into broadly defined goals and objectives and subsequent steps to achieve them (Odongo \& Datche, 2015). Today organisations from both the public and private sectors had taken the practice of strategic planning seriously as a tool that could be utilized to fast track their performance levels. Strategic planning is arguably an important ingredient in the conduct of strategic management. According to Thompson and Stickland (2007), strategic planning was regarded as a management tool that continually and systematically evaluates business identifying its long-term goals and quantifiable objectives. This also involve developing plans to implement, monitor performance, allocate resources, and redefine the plan where need arise. Strategic planning is a key driver of organisational growth, since it emerges as a strategic business partner helping the top management build an organization that should be good today, and for future posterity. According to Thompson and Stickland (2007), a strategic plan is a process that involves assessment of opportunities of an organisation, determining strengths and weakness in a dynamic environment.

According to Kenneth (2006), strategy content was a subset of generally accepted management function in public organisations. Many researchers had used performance to determine the factors that contribute to firm productivity. Arasa and K'Obonyo (2012) examined empirical data from nine surveys (8 in USA and 1 in UK within the manufacturing business) on the relationship between strategic planning and overall firm performance in which they noted mixed reactions. Caeldries and Vandierdonck (1988) surveyed 82 Belgian Business firms and reported a link between strategy and performance. They noted that good strategy enabled a firm to 
strengthen its competitive position, and facilitated integration and coordination of members' behavior. Brenes, Mena, and Molina (2007) observed that the main reason for the introduction of formalized strategic planning was to improve company performance through the development and implementation of better strategies. According to Arasa and K'Obonyo (2012), within the African context, firms that practiced strategic planning recorded higher performance compared to non-strategic planners. Within the contexts of the constitutional requirement Ghana's agenda, the GOG developed an ambitious national plan called the Ghana Shared Growth and Development Agenda (GSGDA, 2010 - 2013). This agenda, which Development Partners (DPs), including USAID, actively supported, was anchored on the following themes: ensuring and sustaining macroeconomic stability, being the overarching goal of the medium-term economic development policy; and achieved and sustained economic stability while placing the economy on a path of higher growth focused to attain a per capita income of at least $\$ 3,000$ by 2020 .

Kenya led as a country in East and Central Africa region in the first years after independence (from Britain) in terms of research institutions with a growing demand for more industrial and academic outputs justifying the fast growing population (GOK, 2007). Local institutions like Kenya medical research institute (KEMRI) had employees' outcry on poor strategic planning at management level, leading to poor research output (Brendan, 2008). This was on the premise that her planning tended to be inflexible and rigid since KEMRI operated in a dynamic environment yet it had poor adaptation of strategies to suit the dynamic research within its context. In agriculture sector the country's main categories of research institutions include: agricultural crop research, livestock research, forestry, fisheries, academic research and socio-economic research. The present work is based on former institutions which were separately mandated to carry agriculture related research and which later formed the present Kenya Agricultural and Livestock Research Organization, namely; Kenya Agricultural Research Institute (KARI), Coffee Research Foundation (CRF), Tea Research Foundation (TRF), and Kenya Sugar Research Foundation (KeSREF). The objective of the present study was to explore employee perception of present level of the employer strategic planning for employee support on daily duty performance.

\subsection{The Study Theories}

\subsubsection{Pecking Order Theory}

In the theory of firm's capital structure and financing decisions, interest is drawn on the pecking order theory or Pecking Order Model that was first suggested by Donaldson in (1961) and modified by Myers and Majluf in (1984). It states that companies prioritize their sources of financing from internal financing to equity. According to the Principle of least effort, or of least resistance, preferring to raise equity as a financing means is normally the last resort. Hence, internal funds were used first, and when that was depleted, debt was issued, and when it was not sensible to issue any more debt, equity was issued. At that level, organisations establish annual objectives and allocate resources in order to formulate strategies to be executed. David (1997) noted that strategy formulation without being implemented did not serve any useful purpose. Thompson and Stickland (2007) viewed implementation as acting on what had to be done internally to put the formulated strategy into place to achieve the targeted results.

Financial and market performance data was of an objective nature, and could in many instances be easily obtained even when the number of organisations under investigation was big. This type of performance was also the most frequent type of performance found in the human resource and management (HRM)-performance literature (Boselie et al., 2009). However, there was also a more subjective side to the financial and market performance data in the research field of HRM and performance - that was perceived as organizational performance, which was often utilized in those instances when objective data was difficult to obtain. Specific examples of financial and market performance were return on assets, return on equity, revenue, market share, and market value. Capital budgeting techniques however, ought to work for the short and long term planning. Financial concepts as stressed in several corporate strategies were considered firm priority (Fruhan 1979; Salter \& Weinhold 1979; Beirman, 1980). The question was: what was the perception of employees in Kenya agriculture sector in terms of strategic planning for higher performance?

\subsubsection{Human Capital Theory}

Human capital development theory originated from Adam Smith. He was credited for concluding that investment in human capital led to greater economic outputs. In the past, economic strength was largely dependent on tangible physical assets such as land, factories and equipment. Labor was a necessary component but increases in the value of the business came from investment in capital equipment. Modern economists seem to concur that education and health care were the key to improving human capital and ultimately increasing the economic outputs of the nation (Becker, 1993). As Barney (1991) observed, the people working in organisations could be a 
source for competitive advantage unlike any other resource, in the way that they could be rare and hard to imitate by competitors. However, one of the main ideologies was still to enhance the attitudes and behavior of employees in order to improve the performance. In a qualitative attempt to get a grip on what characterized commitment based HRM and how the employees experience it, Lowe and Oliver (1991) explored the HR practices/cultures of two companies categorized as high commitment organisations. It was asserted that, recent challenges such as globalisation, and technological evolution had obliged many countries and organizations to seek competitive advantage (Nzuve, 2007). Kenya needed full potential realization as an economic giant that was once better or at bar with South Korea and other Asian Tiger nations such as Singapore and Malaysia at independence. Those Asian countries embraced investment in research and development programs and strengthened research institutions; whereas Kenya concentrated on acquiring the products that those countries created and efficiently delivered external markets (Ombui, Mukulu, \& Waititu, 2014).

In the context of the present study, the human capital theory influences agricultural based research institutions in Kenya based on the ever changing environment especially on firm performance. In addition, the theory was relevant to the present study such that strategic management of human capital was a central pillar in the alignment of firm strategies with agency mission, goals, and objectives through analysis, planning, investment, and management of human capital programs. According to Ragupathi (2013), human capital was an asset to the organization, the value of appreciation with time if provided with the right support as training and development, career advancement opportunities and measures for enhancing 'on the-job satisfaction'. The plan becomes the roadmap for continuous improvement and the framework for transforming the culture and operations of the agency.

\subsubsection{Theory of Constraints}

This theory dates back to Goldratt in the mid-1980s, the theory of constraints (TOC) which evolved from the OPT system. He illustrated the concepts of TOC in form of a novel titled 'The Goal'. Due to some difficulties to implement TOC concepts, a second book was written by Goldratt and Foxt titled 'The Race' (Spencer et al., 1995). The TOC had by then developed into a powerful and versatile management theory. In addition, this theory was expounded on further by Davood Golmohammadi in 2015 while at the University of Massachusetts (UMASS) Boston. The theory concerned on the implementation of materials management under conditions of constraints, hence the name theory of constraints (TOC). In his approach to materials management, a production line of an auto parts manufacturer was studied based on TOC and developed four new executive rules by using simulation tools. These rules were based on investigation of several simulation models. According to Mabin (2003) production planning (PP), scheduling, bottleneck, and drum buffer rope formed the basis. Introduction of competing situations in today's manufacturing environment forced organisations to adopt new production management system (PMS). Within the constraints of a fixed environment the overriding principle was to maximize the production output (Miltenburg, 1997). In the present study it was important to determine level of constraints in agricultural research sector in Kenya.

\subsubsection{Information Theory}

The goal of Information Resource Management (IRM) was to manage information as a corporate resource, in the same way that other organisational resources such as finance, personnel and property were managed. In the absence of such explicit management, different parts of organisation were likely to collect their own copies of information and store them in different formats. Information theory was one of the few scientific fields fortunate enough to have had identifiable beginning by Shannon's in 1948. In the beginning of his studies, Shannon acknowledged the work done before him, by such pioneers as Harry and Hartley at Bell Labs in the 1920s. Though their influence was profound, the work of those early pioneers was limited and focused on their own particular applications. Organisation information theory processing was engineered similarly by Egelhof and the contribution from Powell et al (1997). The theory referred to how a firm facilitated information flow both internally and externally (Powell et al. 1997). The processing of information provided an approach of how information and strategy were integrated. Managers required information to be able to minimize uncertainty. The question to address was how does information flow in Kenyan agriculture research sector?

\section{Methodology}

\subsection{Sample and Sampling Techniques}

The study adopted stratified sampling technique due to homogeneity of the population. Stratified random sampling technique enabled subdivision of subjects into strata hence simplified data collection. According to Baird (2007), stratified sampling technique produced estimates of overall population parameters with greater precision and ensured that a more representative sample was derived from a relatively heterogeneous population. 
Stratification aimed at reducing standard error by providing some control over variance. The study grouped the population into various strata according to the categories of various staff. At least $30 \%$ sample of the population was considered generally acceptable (Kothari, 2004). Yamane (1967) formula was used to determine the appropriate sample size of the study. This was because the target population consisted of a large number of units (Yates, 2004). The researcher assumed 95\% desired level of confidence, which was equivalent to standardized normal deviation value of 1.96, and an acceptable margin of error of 5\% (standard value of 0.05 ). The data was analyzed using descriptive statistics and presented in percentages, proportions and frequency tables.

The Pearson's product moment correlation was used to establish the strength of the relationship between strategic planning and firm performance. Using Yamane (1967) formula, a sample size of three hundred and fifty-two respondents was selected from the population. This sample size was supported by Amin (2005) that population size beyond a certain point (e.g. $\mathrm{N}=5,000$ ), the population size was almost irrelevant and the sample size of 352 was deemed sufficient for the study (Table 1).

Table 1. Showing sample size methodology

\begin{tabular}{lll}
\hline Population & Confidence level & Sampling error \\
\hline 2922 & $95 \%$ & .05 \\
\hline
\end{tabular}

$n=\frac{N}{1+N(e)^{2}}$

Where $\mathrm{N}=$ Population

$\mathrm{e}=$ Expected Error

Sample size $=\frac{2922}{1+2922(0.5)^{2}}=351.836$.

When rounded it $\mathbf{= 3 5 2}$

Samples were selected using stratified random sampling whereby research institutions were put into four strata. By using Fisher's formula, the sample was drawn from each stratum and a total of 352 samples identified from their former naming: KARI 162, CRF 90, TRF 60 and KESREF 40 using simple random sampling where respondents were randomly selected in the various institutions. This gave a total of 352 samples who were paired in the following scores:

$$
r=\frac{n \sum x y-\left(\sum x\right)\left(\sum y\right)}{\sqrt{n \sum x^{2}-\left(\sum x\right)^{2}} \times \sqrt{n \sum y^{2}-\left(\sum y\right)^{2}}}
$$

Where:

N-Number of pairs of scores

$\Sigma X Y-S u m$ of the products of paired scores

$\Sigma \mathrm{X}$-Sum of $\mathrm{x}$ scores

$\Sigma Y$-Sum of y scores

$\Sigma \mathrm{X}^{2}-$ Sum of squared $\mathrm{x}$ scores

$\Sigma \mathrm{Y}^{2}$ - Sum of squared y scores

\subsection{The Ordinal Logistic Regression Technique}

The response variable performance (liquidity) denoted by Y had three levels measured on a three-point Likert scale as high, moderate and low. Therefore, arranging the three levels of $\mathrm{Y}$ in a hierarchical manner gives:

High $>$ moderate $>$ low

Using the ordinal logistic regression technique and assuming a proportional odds model, with the level low taken as the reference category, two ordinal logistic regression models were fitted simultaneously onto the data.

$$
\left[\frac{P(Y=\text { low })}{P(Y=\text { moderate, high })}\right]=\exp \left(\beta_{01}+\beta_{1} X_{1}+\hat{\mathrm{a}}_{2} X_{2}+\beta_{3} X_{3}+\ldots+\beta_{k} X_{k}\right)
$$




$$
\left[\frac{P(Y=\text { low, moderate })}{P(Y=\text { high })}\right]=\exp \left(\beta_{02}+\beta_{1} X_{1}+\beta_{2} X_{2}+\beta_{3} X_{3}+\ldots+\beta_{k} X_{k}\right)
$$

Therefore the categorical explanatory variable $X_{i}$ and the regression co-efficient $\beta_{i}$, the odds ratio denoted by OR was given by:

$$
O R=e^{\beta_{i}}=\exp \left(\hat{\beta}_{i}\right)
$$

In the model, the categorical and the numeric factors were analysed in such a way that:

$x_{i}$ is assigned the value 0 for the reference category and assigned the value 1 for the other category if it represents a categorical variable.

$x_{i}$ is assigned its actual value captured in the questionnaire if it represents a numeric variable.

The technique used the ordinal logistic regression with proportional odds which uses cumulative categories. Therefore, the intercept differs between models, but the regression co-efficient were the same across the fitted models.

\subsection{Assumptions in the Ordinal Logistic Regression Model}

1) Linearity: A linear relationship between each explanatory variable and the logarithm of the response variable.

2) Independence of errors: Data for observational units not being related. Same data not collected from same respondents at different times.

3) No perfect multi-collinearity: The observations being independent and therefore no relationship existing between multiple explanatory variables. This meant the explanatory variables were independent of each other.

\subsection{Interpretation and Inference of the Odds Ratio}

Taking an explanatory variable $\boldsymbol{X}_{\boldsymbol{i}}$ and the corresponding odds ratio OR $=\boldsymbol{e x p}\left(\widehat{\boldsymbol{\beta}}_{\boldsymbol{i}}\right)$. Then this meant that holding other factors constant:

1) The odds of that factor falling in the low category as opposed to the moderate or high categories being OR. This value of OR implied that the explanatory variable category is either more likely or is less likely to fall in the moderate or high categories as compared to the low category depending on whether the difference is above or below the value 1 or $100 \%$.

2) The odds of that factor falling in the low or moderate categories as opposed to the high category is OR. This value of OR implied that the explanatory variable category being either more likely or less likely to fall in the high category compared to the low or moderate categories depending on whether the difference being above or below the value 1 or $100 \%$.

\subsection{Reliability Test Results}

A pilot test was done before embarking on actual data collection activity. Kombo and Tromp (2009) describe a pilot test as a replica and rehearsal of the main survey. The purpose of a pilot test was to enable validity and reliability of research instruments to be determined (Cooper \& Schilder, 2011). This method divides the gathered interviews and questionnaires into two halves and then correlated (Collis \& Hussey, 2003). Responses of the two halves were compared with each other and similarities identified. The more the similarity between the two halves in each question, the greater the reliability, (Zikmund, 2003). The most common internal consistency measure known as Cronbach"s alpha $(\alpha)$ was used. Cronbach"s alpha reliability coefficient value of 0.7 or higher was considered sufficient. Reliability results for all the set of variables in the questionnaires gave a Cronbach Alpha Statistics of more than 0.7 , thus the threshold value of 0.7 were met.

\section{Results and Discussion}

\subsection{Financial Resource Strategic Planning}

Hypothesis $\mathrm{HO}_{l}$ : Strategic financial planning had no significant influence on firm performance in agricultural based research institutions in Kenya. The questionnaires were tested to ascertain validity and relevance. A total of thirty-five questionnaires were randomly distributed to the target population which represented $10 \%$ of the target population. It was found that liquidity, market share, external environment, internal environment, aggressive strategies affected financial plans. The responses were analyzed and results were as indicated the in Table 2 below. 
Table 2. Showing financial resource factors

\begin{tabular}{|c|c|c|c|c|c|c|c|}
\hline \multirow[b]{3}{*}{ Coefficients: } & \multicolumn{3}{|l|}{ Estimates } & \multicolumn{2}{|c|}{ Odds Ratio } & \multirow{2}{*}{\multicolumn{2}{|c|}{$95 \%$ confidence interva }} \\
\hline & Value & Std. Error & z-value & $\exp \left(\hat{\hat{a}}_{i}\right)$ & & & \\
\hline & $\widehat{\hat{a}}_{i}$ & & & Absolute & Percent & Lower & Upper \\
\hline$[$ Liquidity $=1]$ & -1.9235 & 0.4827 & 15.8782 & 0.1461 & $14.6 \%$ & 0.0567 & 0.3763 \\
\hline$[$ Liquidity $=2]$ & 0.3867 & 0.4648 & 0.6923 & 1.4721 & $147.2 \%$ & 0.5920 & 3.6608 \\
\hline$[$ Market_share $=0]$ & 1.3761 & 0.3975 & 11.9878 & 3.9596 & $396.0 \%$ & 1.8169 & 8.6292 \\
\hline [Market_share $=1]$ & 0.8586 & 0.3537 & 5.8944 & 2.3599 & $236.0 \%$ & 1.1799 & 4.7200 \\
\hline [Market_share=2] & 0.8379 & 0.3186 & 6.9163 & 2.3116 & $231.2 \%$ & 1.2379 & 4.3164 \\
\hline [Market_share=3] & 0.0 & & & 1.0 & $100.0 \%$ & & \\
\hline [External_enviro=0] & -0.4572 & 0.4592 & 0.9912 & 0.6331 & $63.3 \%$ & 0.2574 & 1.5571 \\
\hline [External_enviro=1] & -0.5803 & 0.3757 & 2.3850 & 0.5598 & $56.0 \%$ & 0.2680 & 1.1690 \\
\hline [External_enviro=2] & 0.0 & & & 1.0 & $100.0 \%$ & & \\
\hline [Internal_enviro=0] & 0.2002 & 0.3011 & 0.4418 & 1.2216 & $122.2 \%$ & 0.6770 & 2.2042 \\
\hline [Internal_enviro=1] & 0.0 & & & 1.0 & $100.0 \%$ & & \\
\hline [Aggressive_strat $=0$ ] & 0.3187 & 0.3431 & 0.8629 & 1.3754 & $137.5 \%$ & 0.7020 & 2.6946 \\
\hline [Aggressive_strat=1] & 0.2920 & 0.2817 & 1.0743 & 1.3391 & $133.9 \%$ & 0.7709 & 2.3262 \\
\hline [Aggressive_strat=2] & 0.0 & & & 1.0 & $100.0 \%$ & & \\
\hline$[$ Finan_plans_review $=0]$ & -0.2132 & 0.2565 & 0.6906 & 0.8080 & $80.8 \%$ & 0.4888 & 1.3359 \\
\hline$[$ Finan_plans_review $=1]$ & 0.0 & & & 1.0 & $100.0 \%$ & & \\
\hline
\end{tabular}

\subsection{Interpretation of the Odds Ratios and Inference}

Market share: Not important $\hat{\mathrm{a}}_{i}=1.3761$, therefore OR $=\exp \left(\hat{\hat{\mathrm{a}}}_{i}\right)=3.9596$. Therefore, an organisation whose market share rating was not important, hence 3.9596 times more likely to have low liquidity compared to an organisation whose market share rating was high. The 95\% confidence interval for OR $=[1.9169,8.6292]$, excluding 1. Therefore the research results led to rejection of the null hypothesis $\mathrm{H}_{0}$ at the $5 \%$ level of significance on the part of the tested population of Kenya agriculture research sector.

Market share: Low $\hat{\mathrm{a}}_{i}=0.8586$, therefore $\mathrm{OR}=\exp \left(\hat{\mathrm{a}}_{i}\right)=2.3599$. Therefore, an organisation whose market share rating was low by 2.3599 times was more likely to have low liquidity compared to an organisation whose market share rating was high. The 95\% confidence interval for OR [1.1799, 4.7200] excluding 1 . Therefore the research rejected the null hypothesis $\mathrm{H}_{0}$ at the $5 \%$ level of significance for the tested Kenya agriculture sector.

Market share: Moderate $\hat{\mathrm{a}}_{i}=0.8379$, therefore $\mathrm{OR}=\exp \left(\hat{\hat{\mathrm{a}}}_{i}\right)=2.3116$. Therefore, an organisation whose market share rating was moderate was 2.3116 times more likely to have low liquidity compared to an organisation whose market share rating was high. The 95\% confidence interval for OR $=[1.2379,4.3164]$ which excluded 1. Therefore the research rejected the null hypothesis $\mathrm{H}_{0}$ at the $5 \%$ level of significance. The research therefore concluded that the market share makes a significant contribution in determining the liquidity of Kenya agriculture research sector.

External environment: Stable $\hat{\mathrm{a}}_{i}=-0.4572$, therefore $\mathrm{OR}=\exp \left(\hat{\mathrm{a}}_{i}\right)=0.6331$

Therefore, an organisation whose external environment development was perceived as stable was $36.69 \%$ less likely to achieve high liquidity compared to an organisation external environment development was perceived as surprising. The $95 \%$ confidence interval for $\mathrm{OR}=[0.2574,1.5571]$ including 1 . Therefore the research failed to reject the null hypothesis $\mathrm{H}_{0}$ at the $5 \%$ level of significance for the Kenya agriculture sector.

External environment: Changing $\hat{\mathrm{a}}_{i}=-0.5803$, therefore $\mathrm{OR}=\exp \left(\hat{\mathrm{a}}_{i}\right)=0.5598$

Therefore, an organisation whose external environment development was perceived as stable was $44.02 \%$ less likely to achieve high liquidity compared to an organisation external environment development was perceived as surprising. The $95 \%$ confidence interval for $\mathrm{OR}=[0.2680,1.6901]$ which included 1 . Therefore the research failed to reject the null hypothesis $\mathrm{H}_{0}$ at the 5\% level of significance. The research therefore concluded that the developments in the external environment did not make a significant contribution in determining the liquidity for Kenya agriculture research sector.

Internal capability study: No $\hat{\mathrm{a}}_{i}=0.2002$, therefore $\mathrm{OR}=\exp \left(\hat{\mathrm{a}}_{i}\right)=1.2216$

An organisation for which there was study of internal capability was $22.16 \%$ more likely to achieve high liquidity compared to an organisation for which there was no study of internal capability. The $95 \%$ confidence interval for $\mathrm{OR}=[0.6770,2.2042]$ which included 1 . Therefore the research failed to reject the null hypothesis $\mathrm{H}_{0}$ at the $5 \%$ level of significance. The research therefore concluded that the study of internal capability of 
Kenya agriculture research sector organisation did not make significant contribution in determining the liquidity of the organisation.

Aggressive strategies impact: None $\hat{\mathrm{a}}_{i}=0.3187$, therefore $\mathrm{OR}=\exp \left(\hat{\mathrm{a}}_{i}\right)=1.3754$

An organisation for which the aggressive strategies were perceived to have had no impact was $37.54 \%$ more likely to achieve high liquidity compared to an organisation for which the aggressive strategies were perceived to have had major impact. The $95 \%$ confidence interval for $\mathrm{OR}=[0.7020,2.6946]$ which included 1 . Therefore the research failed to lead to rejection of the null hypothesis $\mathrm{H}_{0}$ at the $5 \%$ level of significance. Aggressive strategies impact: Minor $\hat{\mathrm{a}}_{i}=0.2920$, therefore $\mathrm{OR}=\exp \left(\hat{\mathrm{a}}_{i}\right)=1.3391$. Hence, an organisation for which the aggressive strategies were perceived to have had minor impact was $33.91 \%$ more likely to achieve high liquidity compared to an organisation for which the aggressive strategies were perceived to have major impact. The $95 \%$ confidence interval for $\mathrm{OR}=[0.7709,2.3262]$ which included 1 . Therefore the research failed to reject the null hypothesis $\mathrm{H}_{0}$ at the $5 \%$ level of significance. The research therefore concluded that the perception of the impact of aggressive strategies of the institutions did not make a significant contribution in determining the liquidity in Kenya.

Financial plans review Frequency: 2 to 5 years $\hat{\mathrm{a}}_{i}=-0.2132$, therefore $\mathrm{OR}=\exp \left(\hat{\mathrm{a}}_{i}\right)=0.8080$. An organisation for which the financial plans were reviewed with a frequency of 2 to 5 years was $19.20 \%$ less likely to achieve high liquidity compared to an organisation for which the financial plans were reviewed annually. The $95 \%$ confidence interval for $\mathrm{OR}=[0.4888,1.3359]$ which included 1 . Therefore the research failed to reject the null hypothesis $\mathrm{H}_{0}$ at the $5 \%$ level of significance. The research therefore concluded that the frequency of financial plan review in the organisation did not make a significant contribution in determining the liquidity of the research institutions tested. This was also in agreement with an assertion that access to finance could be improved through; developing financial and risk management systems that evaluated the particular characteristics of agriculture and agro-enterprises (Imali \& Oloko, 2015).

\subsection{Human Capital Planning}

Hypothesis $\mathrm{HO}_{2}$ : Human capital resource planning had no significant influence on firm performance in agricultural based research institutions in Kenya. Human capital planning was so important to research institutes since it enabled them to have the desired levels of staff necessary to achieve their objectives. Human capital planning independent variable had a total of nine (9) items. All the items in the variable were confirmed valid due to their factor loading values as indicated in Table 3 below.

Table 3. Showing estimation of parameters and modeling extraction

\begin{tabular}{|c|c|c|c|c|c|c|c|}
\hline \multirow[b]{3}{*}{ Coefficients: } & \multicolumn{3}{|c|}{ Estimates } & \multicolumn{4}{|l|}{ Odds Ratio } \\
\hline & \multirow{2}{*}{$\begin{array}{l}\text { Value } \\
\widehat{\boldsymbol{\beta}}_{i}\end{array}$} & \multirow[t]{2}{*}{ Std. Error } & \multirow[t]{2}{*}{ z-value } & \multirow{2}{*}{$\begin{array}{c}\exp \left(\widehat{\boldsymbol{\beta}}_{i}\right) \\
\text { Absolute }\end{array}$} & \multirow[b]{2}{*}{ Percent } & \multicolumn{2}{|c|}{$95 \%$ confidence interval } \\
\hline & & & & & & Lower & Upper \\
\hline$[$ Liquidity $=1]$ & -1.4234 & 1.0818 & 1.7311 & 0.2409 & $24.1 \%$ & 0.0289 & 2.0077 \\
\hline$[$ Liquidity $=2]$ & 0.8527 & 1.0758 & 0.6283 & 2.3460 & $234.6 \%$ & 0.2848 & 19.3217 \\
\hline$[$ No_of_Empl=0] & 0.3338 & 0.4085 & 0.6679 & 1.3963 & $139.6 \%$ & 0.6270 & 3.1096 \\
\hline [No_of_Empl=1] & 0.4208 & 0.4279 & 0.9672 & 1.5232 & $152.3 \%$ & 0.6585 & 3.5237 \\
\hline [No_of_Empl=2] & 0.8644 & 0.5020 & 2.9651 & 2.3737 & $237.4 \%$ & 0.8874 & 6.3497 \\
\hline [No_of_Empl=3] & 0.1056 & 0.4722 & 0.0500 & 1.1114 & $111.1 \%$ & 0.4405 & 2.8039 \\
\hline [No_of_Empl=4] & 0.0 & & & 1.0 & $100.0 \%$ & & \\
\hline$[$ HRP_Recession $=0]$ & 0.1122 & 0.2357 & 0.2266 & 1.1187 & $111.9 \%$ & 0.7048 & 1.7757 \\
\hline$[$ HRP_Recession=1] & 0.0 & & & 1.0 & $100.0 \%$ & & \\
\hline [HRP_DD_forecast $=0$ ] & 0.3012 & 0.4545 & 0.4393 & 1.3515 & $135.1 \%$ & 0.5546 & 3.2935 \\
\hline [HRP_DD_forecast=1] & 0.3092 & 0.4457 & 0.4812 & 1.3623 & $136.2 \%$ & 0.5687 & 3.2635 \\
\hline [HRP_DD_forecast=2] & 1.9673 & 0.8952 & 4.8292 & 7.1515 & $715.1 \%$ & 1.2370 & 41.3460 \\
\hline [HRP_DD_forecast=3] & 0.0 & & & 1.0 & $100.0 \%$ & & \\
\hline$[$ HRP_alignment $=1]$ & 0.1531 & 1.0279 & 0.0222 & 1.1655 & $116.5 \%$ & 0.1554 & 8.7390 \\
\hline$[\mathrm{HRP}$ _alignment $=2]$ & 0.2774 & 0.9955 & 0.0776 & 1.3197 & $132.0 \%$ & 0.1875 & 9.2874 \\
\hline$\left[\mathrm{HRP} \_\right.$alignment $\left.=3\right]$ & 0.3385 & 0.9940 & 0.1159 & 1.4028 & $140.3 \%$ & 0.1999 & 9.8433 \\
\hline$[\mathrm{HRP}$ _alignment $=4]$ & 0.0151 & 0.9965 & 0.0002 & 1.0152 & $101.5 \%$ & 0.1440 & 7.1586 \\
\hline$[\mathrm{HRP}$ alignment $=5]$ & 0.0 & & & 1.0 & $100.0 \%$ & & \\
\hline
\end{tabular}

The results indicated that human capital planning was influential in predicting employee performance in research institutes in Kenya. Nkomo (2004) indicated that organizations with employees having the right skills tend to 
perform better than those without the skills. The estimation of parameters and modeling extraction system had a total of eighteen items were confirmed valid as follows:

$$
\begin{aligned}
& {\left[\frac{P(Y=\text { low })}{P(Y=\text { moderate, } \text { high })}\right]=\exp \left(-1.4234+0.3338 X_{1}+0.4208 X_{2}+0.8644 X_{3}\right.} \\
& +0.1056 X_{4}+0.1122 X_{5}+0.3012 X_{6}+0.3012 X_{7}+0.3092 X_{8} \\
& +1.9673 X_{9}+0.1531 X_{10}+0.2774 X_{11}+0.3385 X_{12}+0.0151 X_{13} \\
& {\left[\frac{P(Y=\text { low, moderate })}{P(Y=\text { high })}\right]=\exp \left(0.8527+0.3338 X_{1}+0.4208 X_{2}+0.8644 X_{3}\right.} \\
& +0.1056 X_{4}+0.1122 X_{5}+0.3012 X_{6}+0.3012 X_{7}+0.3092 X_{8} \\
& +1.9673 X_{9}+0.1531 X_{10}+0.2774 X_{11}+0.3385 X_{12}+0.0151 X_{13}
\end{aligned}
$$

\subsection{Interpretation of the Odds Ratios and Inference}

No of employees: less than $500 \beta_{i}$ 0.3338, therefore OR $=\exp \left(\hat{\beta}_{i}\right)=1.3963$

An organization with less than 500 employees was $39.63 \%$ more likely to achieve high firm performance as compared to an organization with more than 3000 employees. The $95 \%$ confidence interval for OR $=[0.6270$, 3.1096] which included 1. Therefore the research failed to reject the null hypothesis $\mathrm{H}_{0}$ at the $5 \%$ level of significance for the Kenyan agriculture sector.

Number of employees: 500 to $999 \beta_{i}=0.4208$, therefore $\mathrm{OR}=\exp \left(\hat{\beta}_{i}\right)=1.5232$

Thus, an organization with 500 to 999 employees was $52.32 \%$ more likely to achieve high firm performance as compared to an organization with more than 3000 employees. The $95 \%$ confidence interval for OR $=[0.6585$, 3.5237] which included 1. Therefore the research failed to reject the null hypothesis $\mathrm{H}_{0}$ at the $5 \%$ level of significance. No of employees: 1000 to $1999 \beta_{i}=0.8644$, therefore $\mathrm{OR}=\exp \left(\hat{\beta}_{i}\right)=2.3737$. Therefore, an organization with 1000 to 1999 employees was $37.37 \%$ more likely to achieve high firm performance as compared to an organization with more than 3000 employees. The $95 \%$ confidence interval for OR $=[0.8874$, 6.3497] which included 1 . Therefore the research failed to reject the null hypothesis $\mathrm{H}_{0}$ at the $5 \%$ level of significance.

Number of employees: 2000 to $2999 \beta_{i}=0.1056$, therefore $\mathrm{OR}=\exp \left(\hat{\beta}_{i}\right)=1.1114$

Therefore, an organization with 2000 to 2999 employees was $11.14 \%$ more likely to achieve high firm performance as compared to an organization with more than 3000 employees. The $95 \%$ confidence interval for $\mathrm{OR}=[0.4405,2.8039]$ which included 1 . Therefore the research failed to reject the null hypothesis $\mathrm{H}_{0}$ at the $5 \%$ level of significance. For the number of employees, the research therefore concluded that this variable did not make a significant contribution in determining the firm performance.

HRP importance during recession: Number of $\beta_{i}=0.1122$, therefore OR $=\exp \left(\hat{\beta}_{i}\right)=1.1187$. Thus, an organization whose HR did not improve recession was $11.87 \%$ more likely to achieve high firm performance as compared to an organization whose HRP improved recession. The $95 \%$ confidence interval for OR $=[0.4405$, 2.8039] which included 1 . Therefore the research failed to reject the null hypothesis $\mathrm{H}_{0}$ at the $5 \%$ level of significance.

HRP demand forecast: Trend $\beta_{i}=0.3012$, therefore $\mathrm{OR}=\exp \left(\hat{\beta}_{i}\right)=1.3515$

Therefore, an organization which uses trend technique for HRP demand forecast was $35.15 \%$ more likely to achieve high firm performance as compared to an organization which did not use the technique for HRP demand forecast. The $95 \%$ confidence interval for $\mathrm{OR}=[0.5546,3.2935]$ which included 1 . Therefore the research failed to reject the null hypothesis $\mathrm{H}_{0}$ at the $5 \%$ level of significance.

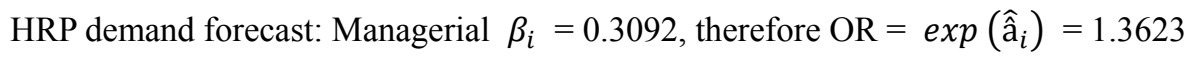

Therefore, an organization whose managerial technique for HRP demand forecast was $36.23 \%$ more likely to achieve high firm performance as compared to an organization which did use the technique for HRP demand forecast. The $95 \%$ confidence interval for $\mathrm{OR}=[0.5687,3.2635]$ which included 1 . Therefore the research failed to reject the null hypothesis $\mathrm{H}_{0}$ at the $5 \%$ level of significance.

HRP demand forecast: Delphi $\beta_{i}=1.9673$, therefore OR $=\exp \left(\hat{\hat{a}}_{i}\right)=7.1515$

Therefore, an organization which uses Delphi technique for HRP demand forecast was 7.1515 times more likely 
to achieve high performance as compared to an organization which did not use technique for HRP demand forecast. The $95 \%$ confidence interval for OR $=[1.2370,41.3460]$ which excluded 1 . Therefore the research rejected the null hypothesis $\mathrm{H}_{0}$ at the $5 \%$ level of significance. For the HRP demand forecast, the research therefore concluded that the trend and managerial techniques both did not make a significant contribution in determining the firm performance, but the Delphi technique makes a significant contribution in determining the liquidity of an organization.

HRP alignment rating: $1 \hat{\mathrm{a}}_{i}=0.1531$, therefore $\mathrm{OR}=\exp \left(\hat{\mathrm{a}}_{i}\right)=1.1635$

Therefore, an organization with an HRP alignment rating of 1 was $16.35 \%$ more likely to achieve high firm performance as compared to an organization with an HRP alignment rating of 5 . The $95 \%$ confidence interval for $\mathrm{OR}=[0.1554,8.7390]$ which included 1 . Therefore the research failed to reject the null hypothesis $\mathrm{H}_{0}$ at the $5 \%$ level of significance. HRP alignment rating: $2 \hat{\mathrm{a}}_{i}=0.2774$, therefore $\mathrm{OR}=\exp \left(\hat{\mathrm{a}}_{i}\right)=1.3197$

Therefore, an organization with an HRP alignment rating of 2 was $31.97 \%$ more likely to achieve high performance as compared to an organization with an HRP alignment rating of 5 . The $95 \%$ confidence interval for $\mathrm{OR}=[0.1875,9.2874]$ which included 1 . Therefore the research failed to reject the null hypothesis $\mathrm{H}_{0}$ at the $5 \%$ level of significance

HRP alignment rating: $4 \hat{\mathrm{a}}_{i}=0.0151$, therefore $\mathrm{OR}=\exp \left(\hat{\mathrm{a}}_{i}\right)=1.0152$

Therefore, an organization with an HRP alignment rating of 4 was $1.52 \%$ more likely to achieve high firm performance as compared to an organization with an HRP alignment rating of 5 . The $95 \%$ confidence interval for $\mathrm{OR}=[0.1440,7.1586]$ which included 1 . Therefore the research results failed to lead to rejection of the null hypothesis $\mathrm{H}_{0}$ at the $5 \%$ level of significance. For the HRP alignment rating, the research therefore concluded that this variable did not make a significant contribution in determining the liquidity of the institutions. In the context of this study, human capital strategic planning was found to be an asset to the institutions examined in the study; the value of appreciation with time if provided with the right support as training and development, career advancement opportunities and measures for enhancing 'on the-job satisfaction' Ragupathi (2013). Based on the study, human capital strategic planning had a significant influence on firm performance in agricultural based research institutions of Kenya.

\subsection{Factor Analysis for Material Resource Strategic Planning}

Hypothesis $\mathrm{HO}_{3}$ : Material resource planning had no significant influence on firm performance in agricultural based research institutions in Kenya. Material resource strategic planning as an independent variable had a total of fourteen (14) items. All the items in the variable were confirmed valid since their factor loading values were more than 0.4 . They were, therefore, retained for subsequent analysis. Material resource factor model to identify the coefficient was computed.at the $95 \%$ confidence level. The results were as indicated in Table 4 below. The results were presented on a Likert scale of absolute, lower and upper. Table 4 shows material resource factors model. performance was found to be estimated to -3.6645 . The odds ratio at $95 \%$ confidence interval upper was 0.1732. The coefficients for regression of all variables indicated significance on firm performance as indicated in Table 4 below. All the four variables should be retained. This indicates that the four had a role to play in the overall model since they influenced institutions (Table 4).

Table 4. Showing material resource factors model

\begin{tabular}{lccccccc}
\hline & Estimates & \multicolumn{5}{c}{ Odds Ratio } \\
\hline & Value & Std. Error & z-value & \multicolumn{2}{c}{$\exp \left(\hat{\hat{a}}_{\boldsymbol{i}}\right)$} & & \multicolumn{2}{c}{ 95\% confidence interval } \\
Coefficients: & $\hat{\mathrm{a}}_{\boldsymbol{i}}$ & & & Absolute & Percent & Lower & Upper \\
{$[$ [performance $=1]$} & -3.6645 & 0.9752 & 14.1214 & 0.0256 & $2.6 \%$ & 0.0038 & 0.1732 \\
\hline
\end{tabular}

\subsection{Material Resource Factors Model}

Material resource factors model was calculated and presented a case processing summary to find the $N$ percentage. Three items were found to have significant loading values as indicated in Table 5 below. The coefficient, the estimates and the Odds ratio are as shown (Table 5). 
Table 5. Showing material resource factors model

\begin{tabular}{|c|c|c|c|c|c|c|c|}
\hline \multirow[b]{3}{*}{ Coefficients: } & \multicolumn{3}{|l|}{ Estimates } & \multicolumn{4}{|c|}{ Odds Ratio } \\
\hline & Value & Std. Error & z-value & $\exp \left(\hat{\hat{a}}_{i}\right)$ & & $95 \%$ co & ence interval \\
\hline & $\hat{\hat{a}}_{i}$ & & & Absolute & Percent & Lower & Upper \\
\hline$[$ Liquidity $=1]$ & -3.6645 & 0.9752 & 14.1214 & 0.0256 & $2.6 \%$ & 0.0038 & 0.1732 \\
\hline$[$ Liquidity $=2]$ & -1.4252 & 0.9544 & 2.2300 & 0.2405 & $24.0 \%$ & 0.0370 & 1.5611 \\
\hline$[$ Supplier agreeStrRM=0] & -0.6296 & 0.8205 & 0.5887 & 0.5328 & $53.3 \%$ & 0.1067 & 2.6608 \\
\hline [Supplier_agreements $=1]$ & -1.0125 & 0.7988 & 1.6068 & 0.3633 & $36.3 \%$ & 0.0759 & 1.7386 \\
\hline [Supplier_agreements $=2]$ & 0.0 & & & 1.0 & $100.0 \%$ & & \\
\hline$[$ Manufacturer_cert $=0]$ & -0.2949 & 0.5879 & 0.2516 & 0.7446 & $74.5 \%$ & 0.2352 & 2.3571 \\
\hline [Manufacturer_cert=1] & -0.4779 & 0.5424 & 0.7763 & 0.6201 & $62.0 \%$ & 0.2142 & 1.7953 \\
\hline [Manufacturer_cert=2] & 0.0 & & & 1.0 & $100.0 \%$ & & \\
\hline
\end{tabular}

Table above shows material resource factor model. The two ordinal logistic regression models for material resource factors were therefore fitted onto the data as derived from Table 5 above and result given by:

$$
\begin{aligned}
& {\left[\frac{P(Y=\text { low })}{P(Y=\text { moderate, } \text { high })}\right]=\exp \left(-3.6645-0.6296 X_{1}-1.0125 X_{2}-0.2949 X_{3}-0.4779 X_{4}\right)} \\
& {\left[\frac{P(Y=\text { low, moderate })}{P(Y=\text { high })}\right]=\exp \left(-1.4252-0.6296 X_{1}-1.0125 X_{2}-0.2949 X_{3}-0.4779 X_{4}\right)}
\end{aligned}
$$

Material supplier agreement: Yes $\hat{\mathrm{a}}_{i}=-0.6296, \quad$ therefore $\mathrm{OR}=\exp \left(\hat{\mathrm{a}}_{i}\right)=0.5328$

An organization which had material supplier agreement was $46.72 \%$ less likely to achieve high firm performance as compared to an organization which material supplier agreement apply. However, the results of the study at the $95 \%$ confidence interval for $\mathrm{OR}=[0.1067,2.6608]$ which included 1 showed contrary. Therefore the research failed to reject the null hypothesis $\mathrm{H}_{0}$ at the $5 \%$ level of significance.

Material supplier agreement: No $\hat{\mathrm{a}}_{i}=-1.0125, \quad$ therefore $\mathrm{OR}=\exp \left(\hat{\mathrm{a}}_{i}\right)=0.3633$

Therefore, an organization which had material supplier agreement was $63.67 \%$ more likely to achieve higher firm performance compared to an organization which material supplier agreement did not apply. The 95\% confidence interval for $\mathrm{OR}=[0.2142,1.7953]$ which included 1 . Therefore the research failed to reject the null hypothesis $\mathrm{H}_{0}$ at the $5 \%$ level of significance. The research therefore concluded that material supplier agreement made significant contribution in determining the firm performance.

Manufacturer certificate required: Yes $\hat{\mathrm{a}}_{i}=-0.2949$, therefore $\mathrm{OR}=\exp \left(\hat{\mathrm{a}}_{i}\right)=74.5 \%$ Therefore an organization in which manufacturer certificate was a requirement was $25.54 \%$ less likely to achieve high firm performance compared to an organization in which manufacturer certificate was not a requirement. The $95 \%$ confidence interval for $\mathrm{OR}=[0.2352,2.3571$ which included 1 .Therefore the research failed to reject the null hypothesis $\mathrm{H}_{0}$ at the $5 \%$ level of significance. Manufacturer certificate required: No $\hat{a}_{i}=-0.4779$, therefore $\mathrm{OR}=\exp \left(\hat{\mathrm{a}}_{i}\right)=0.6201$. Therefore, an organization in which manufacturer certificate was not a requirement was $38.99 \%$ less likely to achieve high firm performance compared to an organization in which manufacturer certificate was a requirement apply. The 95\% confidence interval for OR $=[0.2142,1.7953$ which included 1 . Therefore the research failed to reject the null hypothesis $\mathrm{H}_{0}$ at the $5 \%$ level of significance. The research therefore concluded that manufacturer certificate was not a requirement did not make significant contribution in determining firm performance. Based on the study, material resource strategic planning had a significant influence on firm performance in agricultural based research institutions of Kenya.

\subsection{Information Resource Factors}

Hypothesis $\mathrm{HO}_{4}$ : Information resource planning had no significant influence on firm performance in agricultural based research institutions in Kenya. The research sought to identify the extraction of rotated component and the results were as indicated in Table 6 below. Six (6) items factor loading values worth were significant for the study. Information resource strategic planning is the conscious planning, organizing, realizing, and overseeing of 
the organization's resources involved in creating, storing, processing, transporting, accessing, presenting, and managing the organization's information. Rather than focusing on specific, immediate projects, information resource strategic planning (IRSM). Planning looked at the business strategy and information technology needs of the enterprise as a whole; that helps the organization develop the appropriate information resource project portfolio. Based on this model, the study sought to establish the influence of information resource strategic planning on firm performance in agricultural research based institutions in Kenya. The results were as presented in Table 6 below.

Table 6. Showing information resource factors model

\begin{tabular}{|c|c|c|c|c|c|c|c|}
\hline \multirow[b]{3}{*}{ Coefficients: } & \multicolumn{3}{|c|}{ Estimates } & \multicolumn{4}{|c|}{ Odds Ratio } \\
\hline & \multirow{2}{*}{$\begin{array}{c}\text { Value } \\
\hat{\hat{a}}_{i}\end{array}$} & \multirow[t]{2}{*}{ Std. Error } & \multirow[t]{2}{*}{ z-value } & \multicolumn{2}{|c|}{$\exp \left(\hat{\hat{a}}_{i}\right)$} & \multicolumn{2}{|c|}{$95 \%$ confidence interval } \\
\hline & & & & Absolute & Percent & Lower & Upper \\
\hline$[$ Liquidity $=1]$ & -2.1584 & 0.2182 & 97.8484 & 0.1155 & $11.6 \%$ & 0.0753 & 0.1772 \\
\hline$[$ Liquidity $=2]$ & 0.0960 & 0.1494 & 0.4129 & 1.1008 & $110.1 \%$ & 0.8214 & 1.4752 \\
\hline [Integrated_software $=0]$ & 0.2133 & 0.2479 & 0.7407 & 1.2378 & $123.8 \%$ & 0.7615 & 2.0121 \\
\hline [Integrated_software $=1]$ & 0.0 & & & 1.0 & $100.0 \%$ & & \\
\hline [Computerised_data_entry $=0$ ] & 0.1559 & 0.3066 & 0.2586 & 1.1687 & $116.9 \%$ & 0.6408 & 2.1316 \\
\hline [Computerised_data_entry $=1]$ & 0.0 & & & 1.0 & $100.0 \%$ & & \\
\hline$[$ Backup_procedure $=0]$ & 1.0202 & 0.3937 & 6.7143 & 2.7737 & $277.4 \%$ & 1.2821 & 6.0004 \\
\hline [Backup_procedure $=1]$ & 0.0 & & & 1.0 & $100.0 \%$ & & \\
\hline
\end{tabular}

The two ordinal logistic regression models for financial resource factors were therefore fitted onto the data as derived from Table 6 above and given by:

$$
\begin{gathered}
{\left[\frac{P(Y=\text { low })}{P(Y=\text { moderate }, \text { high })}\right]=\exp \left(-2.1584+0.2133 X_{1}+0.1559 X_{2}+1.0202 X_{3}\right)} \\
{\left[\frac{P(Y=\text { low, } \text { moderate })}{P(Y=\text { high })}\right]=\exp \left(0.0960+0.2133 X_{1}+0.1559 X_{2}+1.0202 X_{3}\right)}
\end{gathered}
$$

Software type: Integrated $\hat{\mathrm{a}}_{i}=0.2133$, therefore $\mathrm{OR}=\exp \left(\hat{\hat{\mathrm{a}}}_{i}\right)=1.2378$. Therefore, the more than $23.78 \%$ result level indicated probability of achieving high firm performance at $95 \%$ confidence interval for $\mathrm{OR}=[0$. $7615,2.0121]$ for the tested institutions.

\section{Conclusion}

The study recommends that financial resource strategic planning be adopted by agricultural research based institutions of Kenya since it had a significant factor in determining firm performance of agricultural research based institutions in Kenya. Financial resource strategic planning had the most statistically significant superiority to other variables in the sense that performance of firm was determined mostly by liquidity. Therefore, research firms that desire to achieve superior performance could excel in pursuing financial resource strategic planning identified in this study. The study further recommends that financial planning be made a guide in helping choice of the right types of investments to fit needs, goals, objectives and risk tolerance since financial resource strategic planning was statistically significant factor in determining firm performance.

Based on the study, the researchers recommend that the agricultural research based institutions adopt human capital strategic planning. The empirical evidence from this study indicated that human capital strategic planning had significant effect on firm performance of research institutions. The results of this study thus provided a valuable reference for managers of institutions in Kenya in terms of what would enable them achieve competiveness and improve their performance. The study recommends that participation of line managers in employee selection process and eventual development of employees in agricultural research based institutions in Kenya, be put in place to ensure that employee skills were always relevant to needs of their respective job positions. This could eliminate instances where employees are found unsuitable for their positions and hence not able to perform effectively making their acquiring irrelevant.

The study recommends agricultural research based institutions to embrace material resource strategic planning in management of stock. It was evident from the study that cost saving mechanism was a major consideration in industries in Kenya due to higher cost of raw materials and energy. The study recommends that the managers of agricultural research based institutions in Kenya deepen their engagement into more cost-effective methods in research planning and management. It was further recommended that agricultural research based institutions in 
Kenya endeavor to acquire affordable and quality sources of raw materials and other value addition management practices that result in reduction of cost be embraced. The study further recommends that strategic relationship management between agricultural research based institutions in Kenya and material supplier relationship management that was advantageous for both suppliers and consumers be inculcated in the supply value chain systems for effective and continued production and efficient firm performance.

The study recommends that agricultural research based institutions embrace information resource strategic planning in management of information technology. It was evident from the study that agricultural research based institutions which had information resource strategic planning in place were more likely to achieve higher firm performance as compared to similar ones which did not have such plans and procedures in place. Based on the study, it was recommended that agricultural research based institutions adopt information resource strategic planning since it was a crucial variable of institutional performance. The study recommends adoption and proper utilization of information resource strategic planning be put in place to increase firm performance in agricultural based research institutions through safeguarding of information and timely production of innovation and technologies. Information resource strategic planning could be resourced properly, managed and mainstreamed into a significant contributor to firm performance.

\section{Acknowledgement}

All respondents of the former institutions (of present KALRO) are acknowledged for their participation in the present work. Dr. D. Mutisya is acknowledged for proof reading and formatting the paper. The researchers wish also to express gratitude to Director General of KALRO who allowed the senior author to carry out the research as part of his PhD Thesis at Jomo Kenyatta University of Agriculture and Technology (JKUAT) and Prof. Elegwa Mukulu, Prof. Margaret Oloko, Dr. Jane Omwenga for their great input and guidance. Others include: Dr. Noah Wawire and Dr. Elijah Gichuru of KALRO Agricultural Mechanization Research Institute and KALRO Coffee Research Institute respectively; for guidance in the work. Finally, Prof. Maria Onyango, Dr. ArvinL Onditi, Dr. Michael Nyagol and Mr. Moses Owana for their Scholarly contribution to this manuscript.

\section{References}

Amin, M. E. (2005). Social science research: Conception, methodology and analysis. Kampala: Makerere University Printery.

Arasa, R., \& K'Obonyo, P. (2012). The relationship between strategic planning and firm Performance. International Journal of Humanities and Social Science Centre for Promoting Ideas, 2(22), 201-213.

Baird, D., \& Fisher, M. (2007). Making mLearning Work: Utilizing Mobile Technology for Active Exploration, Collaboration, Assessment, and Reflection in Higher Education. Journal of Education Technology Systems, 35(1), 3-30.

Barney, J. B. (1991). Firm resources and sustained competitive advantage. Journal of Management, 17, 99-120. https://doi.org/10.1177/014920639101700108

Becker, T. (1990). Job stress and performance controversy: An empirical assessment. Organizational Behavior \& Human Performance, 33(1), 1-21.

Boselie, P., Brewster, C., \& Paauwe, J. (2009). In search of balance-managing the dualities of HRM: an overview of the issues. Personnel Review, 38(5), 461-471. https://doi.org/10.1108/00483480910977992

Brendan, K. (2008). HR Strategic planning in Kenya. A case study of parastatals, survey Report, special Report number 7, Nairobi Kenya.

Brenes, E. R., Mena, M., \& Molina, G. E. (2007). Key success factors for strategy Implementation in Latin America. Journal of Business Research, 61(6), 590-598. https://doi.org/10.1016/j.jbusres.2007.06.033

Caeldries, F., \& Van Dierdonck, R. (1988). How Belgian Business Firms Make Strategic Planning Work. Long Range Planning, 21(2), 41-51. https://doi.org/10.1016/0024-6301(88)90121-5

Chan, G., Barnes-Holmes, D., Barnes-Holmes, Y., \& Stewart, I. (2009). Implicit Attitudes to Work and Leisure among North American and Irish Individuals: A Preliminary Study. International Journal of Psychology and Psychological Science, 9, 317-334.

Cooper, C. R., \& Schindler, P. S. (2008). Business Research Methods (10th ed.). Boston: McGraw-Hill.

David, F. (1997). Concepts of strategic management. New Jersey: Prentice Hall.

Fruhan, W. E. Jr. (1979). Financial Strategy: Studies in the Creation, Transfer and Destruction of Shareholder Value. Homewood IL: Richard D. Irwin, Inc. 
Goldratt, E. M. (1990a). The Haystack Syndrome. Croton-on-Hudson, NY: North River Press.

Hufford, D. (1993). Data administration support for business process improvement. Newsletter, september/october.

Imali, I. K., \& Oloko, M. (2015). Relationship between financial strategies and agribusiness performance a case of Nyeri County in Kenya. International Journal of Management and Commerce Innovations, 3(1), 13-20.

KEMRI. (2015). KEMRI company profile. Retrieved from http://www.kemri.co.ke

Kenneth, L. (2006). Strategy content and organizational performance: An empirical analysis. American society for public Administration Journal, 66(1), 1-154.

Kombo, D. K., \& Tromp, D. L. (2006). Proposal and thesis writing: An introduction. Nairobi: Paulines Publications Africa.

Kothari, C. R. (2004). Research methodology: Methods and techniques (2nd ed.). New Delhi: New Age International Ltd.

Mabin, V. J. (2003). The performance of the theory of constraints methodology Analysis and discussion of successful TOC applications. International Journal of Operations \& Production Management, 23(6), 568-595. https://doi.org/10.1108/01443570310476636

Miltenburg, J. (1997). Comparing JIT, MRP and TOC, and Embedding TOC into MRP. International Journal of Production Research, 35(4), 1147-1169. https://doi.org/10.1080/002075497195597

Mugenda, M. O., \& Mugenda, A. (2008). Research Methods: Qualitative and Quantitative Approaches. Nairobi: African Centre for Technology Studies.

Nkomo, S. M. (2004). Strategic planning for human resources: Let's get started. Long Range Planning Journal, 21(1), 66-72. https://doi.org/10.1016/0024-6301(88)90060-X

Nzuve, S. N. (2007). Elements of Organizational Behavior. Nairobi: University of Nairobi Press.

Odongo, M., \& Datche, O. (2015). Effects of strategic planning activities on organizational growth. International Journal of Scientific and Research Publications, 5(9), 2250-3153.

Ombui, A., Mukulu, E., \& Waititu, G. (2014). The influence of recruitment and selection on the performance of employees in research institutes in Kenya. International Journal of Science and Research, 3(5), 132-138.

Powell, A. (1997). ALPSP Seminar reports. Learned Publishing. https://doi.org/10.1087/09531519750147166

Ragupathi, D. (2013). The financial and human resource management strategies to develop the organization Research Journal of Management Sciences, 2(10), 6-9.

Republic of Kenya. (2007). Kenya Vision 2030: A Globally Competitive and Prosperous Kenya. Nairobi: Government Printer.

Shannon, C. E. (1948). A Mathematical Theory of Communication. Bell System Technical Journal, 27, 379-423. https://doi.org/10.1002/j.1538-7305.1948.tb01338.x

Spencer, N. (1995). Heroic time: Monuments and the past in Messenia, Southwest Greece. Oxford Journal of Archaeology, 14(10), 277-292. https://doi.org/10.1111/j.1468-0092.1995.tb00064.x

Thompson, A., Stickland, A., \& Gamble, J. E. (2007). Crafting and Executing Strategy. Quest for competitive advantage, concept and cases (15th ed.). Boston: McGraw Hill Companies, Inc.

World Bank Report. (2008). Global Crop Diversity Trust. 2006. Global Crop Diversity Trust Pledges. Rome: Global Crop Diversity Trust.

Yamane, T. (1967). Statistics, an Introductory Analysis (2nd ed.). New York: Harper and Row.

Yates, J. S. (2004). Doing Social Science Research. London: Sage Publications in association with the Open University Press.

\section{Copyrights}

Copyright for this article is retained by the author, with first publication rights granted to the journal.

This is an open-access article distributed under the terms and conditions of the Creative Commons Attribution license (http://creativecommons.org/licenses/by/4.0/). 